\title{
O Processo de Decisão de Compra de Viagem de Férias da Família
}

\author{
Decision Making Process of Purchasing Family Vacation Travel \\ El Proceso de Toma de Decisiones de Compra de Viaje de Vacaciones de La Familia.
}

\author{
Marco Antônio Ocke ${ }^{1}$
}

\begin{abstract}
Resumo
Este artigo tem o objetivo de discutir o comportamento de consumo no que se refere à influência dos membros da família no processo de tomada de decisão de compra de viagens de férias. Inúmeras maneiras de examinar o processo de tomada de decisão de compra foram identificadas na literatura, porém, este estudo utilizou o modelo de três etapas do processo de tomada de decisão: reconhecimento do problema, busca por informação e decisão final de compra. Desenvolveu-se um estudo exploratório onde foram coletados 40 questionários entre os dias 15 de Junho e 15 de Julho de 2012 de respondentes que haviam comprado um ou mais pacotes de viagem nos últimos dois anos em uma agência de turismo da cidade de São Paulo. Os resultados indicam que a influência de pais e filhos no processo decisório varia de acordo com as etapas do processo e que apesar de grande parte das decisões sejam tomadas em conjunto, as mulheres apresentam maior influência nos três estágios de tomada de decisão, principalmente na etapa de busca por informação. Neste cenário, o trabalho aponta para a necessidade de uma maior diversidade de pesquisas empíricas sobre o comportamento de consumo das famílias em relação à aquisição de serviços turísticos.
\end{abstract}

PALAVRAS-CHAVE: Comportamento de Consumo, Processo Decisório da Família, Férias, Turismo.

\begin{abstract}
This paper aims to discuss the consumer behavior regarding the influence of family members in decision making process of purchasing family vacation travel. Several ways to examine the decision making process were identify in the literature, however, this work made use of the three stages process: problem recognition, information search and purchase decision. In this sense it was developed an exploratory study where 40 questionnaires were collected between June $15^{\text {th }}$ and July $15^{\text {th }} 2012$, from respondents who had purchased one or more tour packages over the past two years from a travel agency in São Paulo. The results indicate that most part of decisions are taken in group and the role of parents and children in purchasing family vacation varies according to the steps of decision making process; however, women had a greater influence on the three stages of family decision making, especially regarding information search. The results

\footnotetext{
1 Doutorando em Marketing pela Faculdade de Economia, Administração e Contabilidade da Universidade de São Paulo. (FEA - USP). Mestre em Comunicação e Mídia pela Universidade Paulista (Unip). Bacharel em Publicidade e Propaganda pela Universidade Presbiteriana Mackenzie. Professor membro da Universidade Anhanguera/Uniban em regime de dedicação parcial. Brasil. marcoocke@ hotmail.com
} 
indicate the necessity of increasing the range of research on consumer behavior in tourism and family decision making.

KEY WORDS: Consumer Behavior, Family Decision Making, Vacation, Tourism.

\section{Resumen}

Este artículo tiene como objetivo discutir el comportamiento del consumo y la influencia de miembros de la familia en el proceso de toma de decisiones de compra de viaje de vacaciones de la familia. Varias maneras de examinar el proceso de toma de decisiones fueron identificados en la literatura, sin embargo, este trabajo se hizo uso de las tres etapas de proceso: reconocimiento del problema, búsqueda de información y decisión de compra. En este proceso se desarrolló un estudio exploratorio donde 40 cuestionarios fueron recogidos entre el 15 de junio y 15 de julio de 2012 de los clientes que habían comprado uno o más paquetes de viajes en los últimos dos años en una agencia de viajes en São Paulo. Los resultados de este estudio indican que el papel de los padres y los niños en la toma de decisiones de compra de vacaciones de la familia varía en función de los pasos de la toma de decisiones, sin embargo, las mujeres tuvieron una mayor influencia en las tres etapas de la toma de decisiones, especialmente durante la búsqueda de información. Los resultados propone una gama más amplia de la investigación empírica sobre el comportamiento del consumidor en el turismo e la toma de decisiones familiares.

PALABRAS-CLAVE: Comportamiento del consumidor, La toma de decisiones familiares, Vacaciones, Turismo.

\section{Introdução}

A EMBRATUR publica anualmente informações referentes à intenção de viagens dos brasileiros com base em dados coletados numa pesquisa mais ampla, denominada Sondagem de Expectativas do Consumidor, realizada pelo Instituto Brasileiro de Economia (IBRE), da Fundação Getulio Vargas, a qual abarca uma amostra de mais de 2000 domicílios nas seguintes cidades brasileiras: Belo Horizonte, Brasília, Porto Alegre, Recife, Rio de Janeiro, Salvador e São Paulo. Tal pesquisa é realizada por meio de contato telefônico. Os resultados apurados pela sondagem do consumidor em relação à intenção de viagem retratam a expectativa das famílias brasileiras de consumir os serviços relacionados ao turismo nos próximos seis meses. A coleta de dados para a edição de dezembro/2012 foi realizada entre os dias 30 de novembro/2012 e 19 de dezembro/2012. É possível depreender dos achados da pesquisa, que a maioria dos entrevistados tem a intenção de viajar acompanhado, sendo que o perfil do acompanhante é composto por membros da família, tendo em primeiro lugar o 
cônjuge, seguido dos filhos. A tabela a seguir apresenta dados consolidados da sondagem levando em consideração a intenção de viagem com acompanhantes e detalhadas com o tipo de acompanhante que se intenciona viajar.

Tabela 1 - Sondagem do consumidor em relação à intenção de viagem.

\begin{tabular}{|l|r|r|r|r|r|r|r|r|r|r|r|r|r|}
\hline $\begin{array}{l}\text { Acompanhante (\%) } \\
\text { Sozinho (a) }\end{array}$ & JAN & FEV & MAR & ABR & MAI & JUN & JUL & AGO & SET & OUT & NOV & DEZ \\
\hline
\end{tabular}

\begin{tabular}{|c|c|c|c|c|c|c|c|c|c|c|c|c|}
\hline Tipo de Acompanhante (\%) & JAN & FEV & MAR & ABR & MAI & JUN & JUL & AGO & SET & OUT & NOV & DEZ \\
\hline Cônjuge & 52,9 & 55,8 & 48,9 & 48,5 & 50,2 & 49,2 & 47,3 & 51,4 & 50,5 & 48,2 & 50,0 & 46,2 \\
\hline Filhos & 27,8 & 28,6 & 26,8 & 30,2 & 32,0 & 30,6 & 32,7 & 29,5 & 31,8 & 33,0 & 31,2 & 32,7 \\
\hline Outros Parentes & 9,8 & 5,6 & 14,6 & 12,0 & 8,7 & 12,0 & 11,2 & 9,7 & 8,8 & 10,6 & 12,4 & 14,2 \\
\hline Amigos & 6,1 & 8,4 & 6,9 & 7,8 & 8,3 & 6,8 & 6,1 & 6,3 & 6,9 & 6,8 & 5,9 & 5,5 \\
\hline Colegas de Trabalho/ Estudo & 0,2 & 0,3 & 0,2 & 0,1 & 0,2 & 0,1 & 0,1 & 0,3 & 0,1 & 0,1 & 0,0 & 0,1 \\
\hline Outros & 3,2 & 1,3 & 2,6 & 1,4 & 0,6 & 1,3 & 2,6 & 2,8 & 1,3 & 1,3 & 0,5 & 1,3 \\
\hline
\end{tabular}

No que se refere à intenção de viagens a serem realizadas com acompanhantes e de acordo com segmentações específicas desta sondagem, os resultados apontam maior manifestação por pesquisados de todas as faixas de renda familiar, variando, em dezembro/2012, de 78,5\% (segmentação até $\mathrm{R}$ \$ 2.100) a 93,4\% (mais de $\mathrm{R}$ \$ 9.600). Em todos os intervalos de renda da sondagem predomina a realização de viagens com cônjuges e filhos, sendo que os somatórios relativos a essa opção variam de $66,9 \%$ a $83,9 \%$. A intenção de realização de viagens com cônjuges e filhos varia de 63,4\% (respondentes com até 35 anos) a 89,4\% (entre 35 e 44 anos). A atual sondagem indica que os percentuais de propósitos de viagens com acompanhantes variam de 79,3\% (respondentes sem instrução ou com primário incompleto) a $100,0 \%$ (primário completo a $1^{\circ}$ grau incompleto, constituindo nível recorde dessa série histórica). As assinalações referentes às intenções de viagens com cônjuges e com filhos variam de $42,7 \%$ (entrevistados com $1^{\circ}$ grau completo a $2^{\circ}$ grau incompleto) a $84,1 \%$ (pós- 
graduação). A maioria dos entrevistados informou que deverá viajar acompanhada, apurandose tênue majoração percentual nos dois gêneros: 92,9\% de respostas entre homens (contra 92,8\% em dezembro/2011) e 88,8\% entre as mulheres (contra 87,3\%). Quanto aos informantes do gênero masculino, 57,9\% informaram, na presente sondagem, que deverão ir com cônjuges, $30,3 \%$ com filhos, $6,8 \%$ com outros parentes, $3,6 \%$ com amigos, e $1,4 \%$ com outros tipos de acompanhantes. No que diz respeito às entrevistadas, $41,6 \%$ deverão ir com cônjuges, 33,6\% com filhos, $13,4 \%$ com outros parentes, $8,9 \%$ com amigos e 2,5\% com demais tipos de acompanhantes.

Neste contexto, este artigo tem o objetivo de discutir e entender a influência dos membros da família no que diz respeito à tomada de decisão de compra de férias familiares, levando em consideração que cada membro da família tem seus próprios motivos e desejos, enquanto que o grupo apresenta um combinado de determinantes gerando a busca da satisfação individual e coletiva. O fator fundamental no processo decisório para compra de viagens de férias para a família é a combinação da estrutura familiar com a influência que cada membro exerce um sobre o outro ao longo das etapas que compõem o processo de decisão de compra e o resultado final é, geralmente, consequência de um processo de tomada de decisões conjuntas.

O artigo está estruturado de forma a discorrer sobre os principais achados da literatura de comportamento de consumo no turismo e processo decisório da família no que tange as escolhas de viagens a lazer, considerando também os resultados encontrados em pesquisas anteriores. Na sequência, o artigo descreve a metodologia adotada para a pesquisa de campo que procurou encontrar dados referentes ao comportamento de consumo nas viagens de férias da família em linhas gerais, bem como a influência exercida pelos membros da família no processo decisório. A abordagem utilizada adotou a quebra do processo decisório em três fases distintas: (1) iniciação ou reconhecimento do problema; (2) pesquisa e busca por informação e (3) decisão da compra final (DAVIS; RIGAUX, 1974; SZYBILLO; SOSANIE, 1977; NELSON, 1979; HOWARD; MADRIGAL, 1990). Para tal finalidade, desenvolveu-se um estudo exploratório onde foram coletados 40 questionários entre os dias 15 de Junho e 15 de Julho de 2012 de respondentes que haviam comprado um ou mais pacotes de viagem nos últimos dois anos em uma agência de turismo da cidade de São Paulo. Por fim, o artigo analisa os dados resultantes da pesquisa descrevendo as variáveis que compõem o processo 
decisório da família em torno da escolha de produtos turísticos e sugere propostas de desdobramentos relevantes ao estudo proposto.

\section{Processo Decisório da Família no Turismo}

A natureza intangível da oferta do serviço turístico exerce um considerável efeito sobre o consumidor durante o processo de tomada de decisão que envolve a compra. Os produtos do turismo apresentam muitos aspectos distintos e, neste sentido, o comportamento do consumidor será naturalmente diferente daqueles que envolvem o processo decisório de bens de consumo. Para tratar as dadas diferenças, definições e modelos de comportamento do consumidor adaptado ao turismo foram desenvolvidos e, como tais, apresentam dados que variam desde definições mais gerais até modelos mais detalhados (MIDDLETON, 1988; GILBERT, 1991; MATHIESON; WALL, 1982). Todos os modelos proporcionam alguns esclarecimentos sobre o processo de comportamento do consumidor nos estágios de decisão de compra e no pós-compra. Para Swarbrooke (2002) o problema destes modelos é que pouca pesquisa empírica tem sido realizada para testá-los. Ainda, é possível notar que a maior parte dos modelos de comportamento do consumidor de turismo parece ser linear e limitada se comparada aos modelos mais gerais de comportamento do consumidor. Isto ocorre em virtude das diversas características do turismo que implicam uma inevitável complexidade no comportamento de consumo e nos estágios do processo decisório (COOPER, et al., 1993).

Até que ponto o comportamento do consumidor é configurado por seus próprios determinantes pessoais ou externos é algo que apresenta variações complexas. No caso de uma viagem em grupo, seja ele familiar ou de amigos, cada indivíduo tem seus próprios fatores motivacionais, ao passo que o grupo como um todo possui um conjunto de determinantes ocasionando a necessidade de satisfação individual como também coletiva (MIDDLETON, 1994). O fator determinante no mercado familiar, enfoque deste estudo, é a existência dos filhos. Muitas famílias escolhem o tipo de férias com base no alinhamento da estrutura familiar com as características dos destinos e pacotes turísticos oferecidos. O ciclo de vida da família, bem como o número de filhos também exerce um impacto sobre a demanda (SWARBROOKE, 1995). 
Existem basicamente três tipos de tomada de decisão de compra de férias da família. O modelo do marido dominante, da esposa dominante e da decisão conjunta entre marido e mulher (JENKINS, 1978; FILIATRAULT; RITCHIE，1980; NICHOLS; SNEPENGER, 1988; FODNESS, 1992). A decisão de férias é geralmente resultado de tomada de decisões conjuntas, como documentado em estudos de Sharp e Mott (1956) e Cunningham e Green (1974). Davis e Rigaux (1974) também indicaram que o marido e a esposa compartilham as fases de decisão, tais como o reconhecimento do problema, a busca de informações e a decisão final. Pesquisas sugerem que a família tem uma tendência a tomar uma decisão conjunta em reconhecimento do problema e as etapas de decisão final de compra, enquanto que as mulheres desempenham um papel dominante na fase de busca de informação (WANG, et al., 2003). Howard e Madrigal (1990) apontaram para o fato das mães dominarem as decisões de busca por informação ao passo que as crianças estarem apenas significativamente envolvidas nas decisões que se referiam aos serviços de recreação.

Muito embora o reconhecido papel de liderança dos pais no processo decisório, a influência dos filhos não pode ser ignorada. Estudos empíricos vêm tentando testar a relação da influência das crianças e dos pais na tomada de decisões da família. Assael (1995) observou que as crianças desempenham um papel importante na tomada de decisão da família e sua influência varia de acordo com categorias de produtos, serviços e diferentes fases do processo decisório. Howard e Madrigal (1990) apontam que vários estudos verificaram que a relação das influências do marido, esposa ou filhos é susceptível de variar de acordo com o tipo de decisão de compra, a etapa do processo decisório e as características da família.

Swinyard e Sim (1987) concluíram que as crianças são participantes significativas em cada fase do processo de decisão para uma variedade produtos orientados ao público infantil como brinquedos e roupas, assim como também para produtos e serviços consumidos por toda a família tais como planejamento de férias e escolha de restaurantes. Seus estudos indicaram que a influência da criança resultava em $68,7 \%$ no reconhecimento do problema, $39 \%$ na procura por informação, 49,2 \% na decisão final e 20,2 \% na escolha da compra. Numa estrutura similar, Szybillo e Sosanie (1977) indicaram que as crianças estavam envolvidas em cerca de 60-80 por cento de todas as fases do processo decisório. 
Jenkins (1978) identificou que os pais percebem ser altamente influenciados pelos filhos na decisão das atividades que a família vai participar em conjunto, especialmente as decisões de férias. Subsequentemente, Jenkins (1979) demonstrou que, no que diz respeito às férias, 20-35 $\%$ dos pais relataram a influência direta e indireta das crianças como sendo fortes determinantes na escolha do período, localidade, acomodações e atividades. Concluiu que os maridos dominam as responsabilidades de coleta de informação, decisões sobre tempo de férias, o valor gasto em hospedagem e transporte. Crianças influenciam as decisões sobre férias no que diz respeito às atividades e atrações que a envolvem, a seleção do destino e a data das férias. Belch, Belch e Ceresino (1985) também constataram que as decisões financeiras sobre quanto gastar são dominadas pelo marido, no entanto, este tem menos influência na escolha do destino e hospedagem.

Filiatrault e Ritchie (1980) concluíram que os maridos dominavam a tomada de decisão de férias da família junto com as crianças; a tomada de decisão conjunta foi mais frequente com casais sem filhos; a influência dos maridos e esposas nas decisões de férias variou mais em famílias com crianças; crianças exerciam uma influência relativamente pequena na decisão geral processo. Embora algumas pesquisas tenham indicado que os filhos têm certa influência no processo de decisão da família, outros estudos sugeriram que crianças têm pouca influência sobre quanto gastar, onde efetuar a compra, e a decisão final (FOXMAN, TANSUHAJ, EKSTROM, 1989).

\section{Metodologia de Pesquisa de Campo}

Inúmeras maneiras de examinar o processo de tomada de decisão de compra foram identificadas na literatura. Por conseguinte, este estudo utilizou o modelo de três etapas do processo de tomada de decisão: o reconhecimento do problema, busca por informação e decisão final de compra. Engel, Blackwell, e Kollat (1978) descriminaram cinco fases importantes no processo de tomada de decisão em comportamento do consumidor: (1) o reconhecimento do problema; (2) busca por informação; (3) avaliação e alternativa; (4) escolha e (5) os resultados. O referido processo decisório de cinco estágios envolve comportamentos pós-compra e embora seja importante, vai além do escopo deste artigo. Além disso, investigações têm sugerido que os consumidores avaliam as informações 
simultaneamente com a busca (KATONA; MUELLER, 1954). Neste pesquisa, foi eliminada também a fase de avaliação das alternativas pela dificuldade prática de pedir aos entrevistados quebrar a sua tomada de decisões em muitos estágios diferentes (DAVIS; RIGAUX, 1974).

Para o desenvolvimento deste artigo, utilizou-se a abordagem mais freqüente de quebrar o processo de decisão em três fases distintas: (1) iniciação ou reconhecimento do problema; (2) pesquisa e busca por informação e (3) decisão da compra final (DAVIS; RIGAUX, 1974; SZYBILLO; SOSANIE, 1977; NELSON, 1979; HOWARD; MADRIGAL, 1990). Swarbrooke e Horner (2002) descrevem, de maneira geral, a etapa do reconhecimento do problema como o primeiro estágio do processo decisório sendo resultante da relação entre o estado atual do consumidor e aquilo que se deseja. Neste contexto, a busca por informação trata de encontrar as possíveis soluções para o problema que foi reconhecido ao passo que a decisão de final compra concluí o processo.

Este estudo exploratório buscou encontrar dados referentes ao comportamento de consumo na aquisição de viagens de férias da família de uma maneira geral e, em caráter específico, a influência exercida pelos membros da família no processo de tomada de decisão de compra de férias. Como técnicas de coleta de dados foram enviados por email 120 questionários durante o período compreendido entre os dias 15 de Junho e 15 de Julho de 2012. Os respondentes foram escolhidos para participar da pesquisa a partir de uma lista de contatos de clientes que haviam comprado um ou mais pacotes de viagem nos últimos dois anos em uma agência de viagens da cidade de São Paulo. Ao final do período de coleta, foram adequadamente respondidos e devolvidos 40 questionários.

O questionário foi constituído de duas partes. Na primeira, os respondentes foram questionados sobre variáveis sociodemográficas incluindo gênero, idade, núcleo familiar e renda. Além disso, de forma mais generalizada, foram acessadas as preferências sobre o perfil de viagem de férias que os respondentes já haviam consumido ou estavam prestes a realizar. $\mathrm{Na}$ segunda parte, o questionário buscou avaliar a influência de pais e filhos na aquisição de um pacote de viagem de férias para a família. Neste contexto, os respondentes foram solicitados a indicar o nível de influência que cada membro da família exerceu em cada um dos três estágios do processo decisório (reconhecimento do problema, busca por informação e 
decisão de compra). Foi utilizada uma escala de seis pontos indo de "nenhuma influência" a "total influência" (BELCH et al., 1985).

A mesma escala foi utilizada para avaliar a influência dos membros da família em outras decisões para compra de férias incluindo: o destino (para onde ir), o orçamento (quanto dinheiro para gastar), período (tempo para gastar), hospedagem (onde ficar), partida e chegada (quando ir e quando voltar) (BELCH et al., 1985; SZYBILLO; SOSANIE, 1977). Foram avaliadas também, as decisões referentes à companhia aérea, serviços alimentares, transportes, compras, excursões opcionais, agência de viagens e tipos de atividades e atrações (JENKINS, 1979).

\section{Análise dos Resultados}

No que tange às características gerais das famílias acessadas na pesquisa, a grande maioria dos respondentes é do sexo feminino (70\%), ao passo que $30 \%$ dos questionários foram preenchidos por homens conforme indicado no Quadro 1. A idade média dos respondentes variou entre 30 e 50 anos de idade, sendo a maioria (18\%) compreendida entre 31 e 40 anos e $11 \%$ compreendida entre 41 e 50 anos de idade. A composição de núcleo familiar tradicional prevaleceu sobre outras composições, integrando um total de $75 \%$. A renda familiar, em sua maioria, variou entre $\mathrm{R} \$ 3$ mil e $\mathrm{R} \$ 9$ mil sendo 32,5\% compreendendo renda entre $\mathrm{R} \$ 3$ mil e R\$6mil, enquanto que 27,5\% se referiram a renda entre R\$6mil e R\$9mil. O número de filhos nas famílias dos respondentes variou em sua maioria entre um e dois, ao passo que a minoria dos respondentes constituía família de casal sem filhos ou casais com três filhos ou mais. Ainda, a idade dos filhos mais velhos em cada família prevaleceu entre 7 e 12 anos (57,5\%).

\begin{tabular}{|l|c|c|}
\hline \multicolumn{1}{|c|}{ Variáveis } & Número (=40) & EM \% \\
\hline Gênero & 12 & 30 \\
Masculino/Pai & 28 & 70 \\
Feminino/Mãe & 07 & 17,5 \\
\hline Idade & 18 & 45 \\
Abaixo de 30 & 11 & 27,5 \\
31-40 & 04 & 10 \\
41-50 & & \\
Acima de 50 & & \\
\hline
\end{tabular}




\begin{tabular}{|l|c|c|}
\hline Núcleo Familiar & 06 & 15 \\
Pai/Mãe Solteiro(a) & 30 & 75 \\
Família Nuclear & 04 & 10 \\
Três gerações & 07 & 17,5 \\
\hline Renda Familiar (mensal) & 13 & 32,5 \\
Abaixo de R\$3 mil & 11 & 27,5 \\
R\$3-6 mil & 09 & 22,5 \\
R\$ 6 - mil & & \\
Acima de R 9 mil & 02 & 5 \\
\hline Número de Filhos & 17 & 42,5 \\
Nenhum & 13 & 32,5 \\
Um & 08 & 20 \\
Dois & & \\
Três ou mais & & 22,5 \\
\hline Idade do Filho Mais Velho & 09 & 57,5 \\
$0-6$ anos & 23 & 20 \\
$7-12$ anos & 08 & \\
13 - 18 anos & & \\
& & \\
\hline
\end{tabular}

Quadro 1: Características dos respondentes.

\subsection{Frequência das viagens}

O Quadro 2 revelou que pouco mais de um terço (35\%) indicou que realiza viagens em família duas vezes ao ano. A maioria dos respondentes declarou viajar em família apenas uma vez ao ano $(42,5 \%)$, enquanto outros $(17,5 \%)$ realizam viagens mais frequentes, três vezes ao ano ou mais. Apenas 5\% declararam não realizar viagem alguma durante o ano, ou apenas quando há tempo livre disponível.

\begin{tabular}{|l|c|c|}
\hline \multicolumn{1}{|c|}{ Frequência } & Número (=40) & EM \% \\
\hline Nenhuma & 01 & 2.5 \\
\hline Uma vez ao Ano & 17 & 42,5 \\
\hline Duas Vezes ao Ano & 14 & 35 \\
\hline Três Vezes ao Ano & 05 & 12,5 \\
\hline Todos os Meses & 02 & 5 \\
\hline $\begin{array}{l}\text { Somente no Tempo Livre } \\
\text { Disponível }\end{array}$ & 01 & 2,5 \\
\hline
\end{tabular}

Quadro 2: Frequência anual das viagens de família. 


\subsection{Tipo de viagem}

Conforme representado no Quadro 3, das opções propostas para realização de viagem de férias, as respostas apresentaram predominante interesse na realização de compras $(62,5 \%)$, seguidas por estadas em resorts $(57,5 \%)$, viagens em cruzeiros marítimos (47,5\%), visitas a parques temáticos (45\%). Em contrapartida, os índices de menor interesse em realizar as viagens foram representados por visitas a amigos e parentes (20\%), turismo de aventura $(15 \%)$ e turismo religioso $(5 \%)$.

\begin{tabular}{|l|c|c|}
\hline \multicolumn{1}{|c|}{ Tipo de Viagem } & Número (>40) & Em \% \\
\hline Viagem para Compras & 25 & 62,5 \\
\hline Resorts & 23 & 57,5 \\
\hline Cruzeiros Marítimos & 19 & 47,5 \\
\hline Parques Temáticos & 18 & 45 \\
\hline $\begin{array}{l}\text { Visita a Amigos e } \\
\text { Parentes }\end{array}$ & 08 & 20 \\
\hline Turismo de Aventura & 06 & 15 \\
\hline Turismo Religioso & 02 & 5 \\
\hline
\end{tabular}

Quadro 3: Preferência pelo tipo de viagem de férias da família.

\subsection{Investimento financeiro em viagens de férias}

Nota-se a partir dos dados apresentados no Quadro 4 que o valor investido na realização das férias familiares varia de acordo com o turismo doméstico e internacional. No que diz respeito às viagens realizadas dentro do próprio país, o investimento varia, em sua maioria (70\%) entre $\mathrm{R}$ \$ 1mil e R\$5mil, ao passo que em $72,5 \%$ da realização de viagens internacionais, o investimento supera $\mathrm{R} \$ 2 \mathrm{mil}$, chegando até $\mathrm{R} \$ 6 \mathrm{mil}$. Ainda, $15 \%$ das viagens domésticas recebem um investimento acima de $\mathrm{R} \$ 5$ mil, enquanto que em 17,5\% das viagens internacionais são alocados mais de R \$6mil. 


\begin{tabular}{|l|c|c|}
\hline Investimento Financeiro & Número (=40) & EM \% \\
\hline Turismo Doméstico & 6 & 15 \\
Abaixo de R\$1 mil & 14 & 35 \\
R \$ - 3 mil & 14 & 35 \\
R \$ - 5 mil & 6 & 15 \\
Acima de R 5 mil & & \\
\hline Turismo Internacional & 12 & 10 \\
Abaixo de R \$2 mil & 17 & 30 \\
R 2 - 4 mil & 7 & 42,5 \\
R 4 - 6 mil & & 17,5 \\
Acima de R 6 mil & & \\
\hline
\end{tabular}

Quadro 4: Valor gasto com as férias da família.

\subsection{Influência dos Membros da Família}

Como o Quadro 5 revela, diferenças significativas foram identificadas em cada um dos três estágios do processo decisório. Nos estágios de reconhecimento do problema e decisão final, a influência dos pais é significativamente mais elevada do que a da criança e nenhuma diferença significativa foi encontrada entre marido e mulher. Aparentemente, nestas duas etapas as decisões conjuntas são dominantes. No entanto, no que diz respeito ao estágio de busca por informação, uma diferença significativa foi encontrada entre marido, esposa e criança e, como a média da pontuação revela, nesta fase a mulher é o principal agente de pesquisa por informação. A criança mostra maior grau de influência na etapa de reconhecimento do problema e é mais baixa no estágio de busca de informações e decisão final de compra. Este resultado é bastante consistente com Belch, Belch e Ceresino (1985).

Os resultados apoiam os achados anteriores de Howard e Madrigal (1990), estudo que concluiu que as mães exercem uma influência significativa no processo decisório, especialmente na busca por informação e nas fases finais de decisão. Um estudo prévio (SWINYARD; SIM 1987) indicava que as crianças participam muito mais no reconhecimento do problema (68,7 \%) do que na busca de informações (39\%). Ainda de acordo com o estudo, a participação dos filhos na decisão final é de 49,2\%. Como o Quadro 5 demonstra, a criança tem muito mais influência no reconhecimento do problema, seguido pela decisão final de compra e por último no processo de busca por informação. 


\begin{tabular}{|l|c|c|c|}
\hline \multicolumn{1}{|c|}{$\begin{array}{c}\text { Estágios do } \\
\text { Processo Decisório }\end{array}$} & Marido & Esposa & Criança \\
\hline $\begin{array}{l}\text { Reconhecimento do } \\
\text { Problema }\end{array}$ & 4,29 & 4,69 & 3,27 \\
\hline $\begin{array}{l}\text { Busca por } \\
\text { Informação }\end{array}$ & 4,12 & 4,72 & 1,79 \\
\hline Decisão de Compra & 4,64 & 4,84 & 2,62 \\
\hline
\end{tabular}

Quadro 5: Influência dos membros da família no processo de decisão de compra de viagem de férias.

Obs: Cada pontuação representa a média de influência de cada membro dentro de uma escala de (1) nenhuma influência e (6) total influência.

O Quadro 6 mostra a relação entre o subproduto da viagem de férias com a tomada de decisão por parte dos membros da família. Os resultados revelam que, entre os 12 itens descritos, os que prevaleceram nas considerações dos inquiridos com $85 \%$ foram a escolha do destino turístico e o período da viagem. Foi detectado que marido e esposa tomam decisões conjuntas em nove categorias. Curiosamente, a mulher tem substancialmente mais influência em três de doze categorias avaliadas, sendo estas as decisões relativas à hospedagem, realização de compras e escolha da agência de viagens.

\begin{tabular}{|l|c|c|c|}
\hline Decisões de Viagem & $\begin{array}{c}\text { Tomador de } \\
\text { Decisão }\end{array}$ & Número & EM \% \\
\hline Destino & Em Conjunto & 34 & 85 \\
\hline Orçamento & Em Conjunto & 28 & 70 \\
\hline Período/Dias & Em Conjunto & 34 & 85 \\
\hline Hospedagem & Esposa & 24 & 60 \\
\hline Data da Viagem & Em Conjunto & 32 & 80 \\
\hline Cia Aérea & Em Conjunto & 20 & 50 \\
\hline Serviços de A\&B & Em Conjunto & 18 & 45 \\
\hline Transportes & Em Conjunto & 12 & 30 \\
\hline Compras & Esposa & 22 & 55 \\
\hline Excursões Opcionais & Em Conjunto & 24 & 77,5 \\
\hline Agência de Viagem & Esposa & 31 & $80 \%$ \\
\hline Atividades e Atrações & Em Conjunto & 32 & \\
\hline
\end{tabular}

Quadro 6: Relação dos membros da família com o processo de tomada de decisão.

Ainda no que se refere aos subprodutos da viagem em relação à influência exercida pelos membros da família, as médias encontradas embasam os resultados apresentados acima, conforme demonstrado no Quadro 7. Apesar da maioria das decisões serem tomadas em conjunto, a 
influência da mãe reflete médias mais altas nas decisões relativas a compras $(4,92)$ na definição do meio de hospedagem $(5,10)$ e na escolha da agência de viagens $(5,03)$. A criança tem mais influência nos tipos de atividades $(4,22)$ e na data da viagem $(3,50)$, ao passo que exerce menor influência na definição do orçamento $(1,38)$ e na escolha da agência de viagens $(1,64)$.

\begin{tabular}{|l|c|c|c|}
\hline Decisões de Viagem & Marido & Esposa & Criança \\
\hline Destino & 4,47 & 4,82 & 2,69 \\
\hline Orçamento & 4,80 & 4,64 & 1,38 \\
\hline Período/Dias & 4,72 & 4,51 & 3,11 \\
\hline Hospedagem & 4,52 & 5,10 & 2,55 \\
\hline Data da Viagem & 4,60 & 4,49 & 3,50 \\
\hline Cia Aérea & 4,83 & 5,05 & 2,59 \\
\hline Serviços de A\&B & 4,26 & 4,74 & 3,22 \\
\hline Transportes & 4,85 & 4,72 & 2,80 \\
\hline Compras & 4,07 & 4,92 & 2,32 \\
\hline Excursões Opcionais & 4,61 & 4,87 & 1,97 \\
\hline Agência de Viagem & 4,64 & 5,03 & 1,64 \\
\hline Atividades e Atrações & 4,78 & 5,11 & 4,22 \\
\hline
\end{tabular}

Quadro 7: Influência dos membros da família no processo de decisão de compra de viagem de férias.

Obs.: Cada pontuação representa a média de influência de cada membro dentro de uma escala de (1) nenhuma influência e (6) total influência.

\section{Considerações Finais}

Dados secundários apontados pelas pesquisas de hábitos de consumo em turismo pelas famílias brasileiras apresentados neste artigo indicam que, no que se refere à intenção de viagens a serem realizadas com acompanhantes, a maioria dos entrevistados demonstra a intenção de realização de viagens acompanhada por membros da família, sendo os cônjuges os principais acompanhantes mencionados nas pesquisas, seguidos pelos filhos. Tais resultados se repetem independentemente da renda familiar, faixa etária, grau de instrução e gênero dos entrevistados. A indústria do turismo tem se esforçado para atrair o mercado da família, mas quase sempre partem do estereótipo do núcleo familiar com dois adultos e alguns filhos, necessitando ainda uma compreensão mais complexa das relações que compõem a estrutura familiar e o processo de decisão de compra. A compreensão da influência dos membros da família no processo de tomada de decisão de compra de férias é uma questão importante para o desenvolvimento de pesquisas acadêmicas. 
Levando em consideração as limitações da pesquisa de campo que contou com a apuração de 40 questionários respondidos em um período relativamente curto, os resultados deste estudo indicam que o papel dos pais e dos filhos na tomada de decisões para compra de férias da família varia de acordo com as etapas do processo decisório. Ainda, em virtude de a pesquisa ter sido realizada durante as férias de inverno no Brasil, há uma maior tendência de comercialização de pacotes de viagens para o exterior e para regiões do Nordeste brasileiro, desta forma, é possível ponderar que resultados diferentes podem surgir em pesquisas realizadas em outras épocas do ano. Além disso, o presente estudo não levou em consideração diferentes tipos de pacote de viagens e produtos agregados e estas variáveis podem influenciar resultados de pesquisas sobre o assunto.

Com relação ao processo de tomada de decisão de compra de viagem de férias da família, a colaboração conjunta entre homens e mulheres é uma indicação positiva de compartilhamento dentro do núcleo familiar. Isto implica que tanto o marido quanto a esposa têm a sua própria quota de participação para planejar e executar suas atividades turísticas, incluindo férias, passeios, e semelhantes. Decisões conjuntas foram encontradas no reconhecimento do problema e nas etapas finais de decisão enquanto que as mulheres apresentaram aspectos dominantes na fase de busca de informação e, de acordo com a pontuação média, apresentam níveis mais elevados do que o marido nos três estágios de tomada de decisão.

Estudos prévios indicavam que as crianças são participantes significativas nos planos de férias, no entanto, os pais continuam a ser os mais importantes agentes de decisão dentro do processo, enquanto crianças partilham influências menos significativas, aparecendo em geral na fase de reconhecimento do problema. Jenkins (1978) encontrou uma predominância do marido em relação à coleta de informações, tempo de férias, quantia financeira para gastar e as decisões de hospedagem. No entanto, o resultado deste estudo apresenta resultados diferentes. Ao passo que decisões referentes ao orçamento e período de férias são tomadas em conjunto, no que diz respeito à escolha do hotel, a esposa apresenta característica dominante. De alguma forma, isso pode refletir a existência de um número crescente de famílias de renda dupla, proveniente de pai e mãe e, desta forma, com a participação ativa da mulher, os casais têm que pensar em conjunto sobre a duração e despesas da viagem. 
Em geral, é possível absorver desta pesquisa a importância do papel de mulher no processo decisório da família. A partir dos resultados encontrados, marido e mulher decidem mutuamente um total de 09 de 12 itens relacionados às viagens, enquanto que a esposa domina os outros três itens (hospedagem, compras e agência de viagens). Tal resultado indica que a mulher apresenta influência bastante significativa nas decisões de compra de férias da família. No entanto, este resultado é contrário ao achado em Belch et al. (1985) que identificou que a influência do marido é maior do que mulher em quatro de cinco áreas específicas de férias decisão (orçamento, hospedagem, destino, atividades.) Obviamente, como encontrado no presente estudo, o papel que a mulher desempenha no processo de tomada de decisão é muito mais relevante.

Este artigo buscou ampliar os domínios teóricos utilizados em turismo a partir da compreensão do comportamento do consumidor e do processo de tomada de decisões. No entanto, pesquisas empíricas ainda são necessárias para incrementar o conhecimento e estender a epistemologia da tomada de decisões viagens em família. Com base nos achados é possível depreender uma variedade de papéis exercidos pelos membros da família no processo de decisão de compra em turismo que podem ser considerados na realização de futuros estudos.

\section{Referências}

ASSAEL, H. Consumer behavior and marketing action. $5^{\text {a }}$ ed.Boston, MA. Ed.Kent Publishing Company. 1995

BELCH, G. E.; BELCH, M. A.; CERESINO, G. Parental and teenage child influences in family decision making. Journal of Business Research, v.13, n.2, p.163-176. 1985

COOPER, C.; FLETCHER,J.;GILBERT,D.; WANHILL,S. Tourism. Principles and Practice. Ed. Pitman Publishing, Great Britain. 1993.

CUNNINGHAM, I. C. M.; GREEN, R. T. Purchasing roles in the US family, 1955 and 1973. Journal of Marketing, v.38, n.4, p. 61-64. 1974

DAVIS, H. L. Measurement of husband-wife influence in consumer purchase decisions. Journal of Marketing Research, v.8, n.3, p. 305-312. 1971

DAVIS, H. L. Decision making within the household. Journal of Consumer Research, v.2, n.4, p. 241 260. 1976

DAVIS, H. L.; RIGAUX, B. P. Perception of marital roles in decision processes. Journal of Consumer Research, v.1, n.1, p. 51-62. 1974 
EMBRATUR. Sondagem do Consumidor - Intenção de Viagem. Dezembro/2012. Disponível: http://www.dadosefatos.turismo.gov.br/dadosefatos/conjuntura_economica/sondagem_consumidor_vi agem/ Acesso em 10 Set. 2013

ENGEL, J. F.; BLACKWELL, R. D.; KOLLAT, D. T. Consumer behavior $3^{\text {a }}$ ed. Chicago. Ed. The Dryden Press. 1978

FILIATRAULT, P.; RITCHIE, J. R. B. Joint purchasing decisions: A comparison of influence structure in family and couple decision making units. Journal of Consumer Research, v.7, n.2, p. 131140. 1980

FODNESS, D. The impact of family life cycle on the vacation decision-making process. Journal of Travel Research, v.31, n.2, p.8-13. 1992

FOXMAN, E. R.; TANSUHAJ, P. S.; EKSTROM,K. M. Family members' perceptions of adolescents' influence in family decision making. Journal of Consumer Research, v.15, n.4, p. 482491. 1989

GILBERT.D.C. An examination of the consumer decision process related to tourism. In C. P. Cooper. Progress in Tourism, Recreation and Hospitality Management. v.3. Ed. Belhaven, Londres, 1991.

HOWARD, D. R.; MADRIGAL, R. Who makes the decision: The parent or child? The perceived influence of parents or children on the purchase of recreation services. Journal of Leisure Research, v.22, n.3, p.244-258. 1990

JENKINS, R. L. Family vacation decision-making. Journal of Travel Research, v.16, n.4, p.2-7. 1978

JENKINS, R. L. The influence of children in family decision making: parents' perceptions. In W. L. Wilkie (Ed.), Advances in consumer research, v.6,p. 413-418. Ann Arbor: Association for Consumer Research. 1979

KATONA, G.; MUELLER, E. A study of purchase decisions. In L. H. Clark (Ed.), Consumer behavior, v.1, p.30-53. Ed: New York University Press. 1954

KOTLER, P.; BOWEN, J.; MAKENS, J. Marketing for hospitality and tourism. $2^{\mathrm{a}}$ ed. Londres. Ed.Prentice-Hall. 1999

MATHIELSON, A.; WALL, G. Tourism: Economic, Physical and Social Impact. Ed. Longman. Londres, 1994.

MIDDLETON, V.T.C., Marketing in Travel and Tourism. Ed.Butterworth-Heinemann, Oxford. 1988.

NELSON, J. E. Children as information sources in the family decision to eat out. In W. L. Wilkie (Ed.), Advances in consumer research, v. 6. p. 419-423. Ann Arbor: Association for Consumer Research. 1979

NICHOLS, C. M.; SNEPENGER, D. J. Family decision making and tourism behavior and attitudes. Journal of Travel Research, v.26, n.4, p. 2-6. 1988

SHARP, H.;MOTT, P. Consumer decisions in the metropolitan family. Journal of Marketing, v.21, n.2, p.149-156. 1956

SWARBROOKE, J. The Development and Management of Visitor Attractions. Ed. ButterworthHeinemann, Oxford. 1995

SWARBROOKE, J.; HORNER, S. O Comportamento do Consumidor no Turismo. Ed. Aleph, São Paulo. 2002

SWINYARD, W. R.; SIM, C. P. Perception of children's influence on family decision processes. The Journal of Consumer Marketing, v.4, n.1, p.25-38. 1987 
SZYBILLO, G. J.; SOSAINE, A. Family decision making: Husband, wife and children. In W. D. Perreault Jr.(Ed.), Advances in consumer research, v.4, p. 46-49. Atlanta: Association for Consumer Research. 1977

WANG,C.K.; HSIEH,T.A.; YEH,C.Y; TSAI,W.C. Who is the decision maker: the parents or the child in group package tours? Tourism management, v.25, p. 183-194. 2004

Recebido em: 01/09/2012 (1 ${ }^{\text {a }}$ versão $)$ 24/09/2013 ( $2^{\mathrm{a}}$ versão)

Aprovado em: 05/11/2013 